\title{
Administrando o Risco: uma Teoria Substantiva da Adaptação Estratégica de Pequenas Empresas a Ambientes Turbulentos e com Forte Influência Governamental
}

\author{
Rodrigo Bandeira-de-Mello \\ Cristiano José Castro de Almeida Cunha
}

\begin{abstract}
Resumo
O comportamento estratégico de pequenas empresas em contexto de turbulência ambiental causado, principalmente, pela influência governamental, não consegue ser suficientemente explicado pelas perspectivas teóricas existentes na literatura. Com o intuito de gerar uma teoria substantiva que explique tal comportamento, foi conduzido um estudo de caso, utilizando os procedimentos metodológicos da Grounded Theory. Os dados foram obtidos por meio da análise de 20 anos da história de uma empresa típica do setor da construção de edificações. Cerca de 595 minutos de entrevistas com cinco dirigentes foram analisadas com o apoio do software ATLAS/ti. Os dados revelaram que a adaptação estratégica da firma a um ambiente turbulento e com forte influência governamental pode ser explicada, na ótica dos dirigentes, por um processo social denominado administração do risco, no qual a busca por posições seguras e livres de risco são priorizadas em detrimento da maximização dos resultados econômicos. A teoria substantiva gerada explica sob quais condições determinadas formas de administrar o risco são utilizadas. O contraste dos resultados com a literatura existente na área revelou que as principais perspectivas teóricas podem ser refinadas para aumentar sua aderência ao contexto investigado.
\end{abstract}

Palavras-chaves: adaptação estratégica; ambientes turbulentos; pequenas empresas; grounded theory.

\begin{abstract}
When one considers a context in which the government drives institutional and disruptive economic changes, affecting the strategic management of small firms, mainstream literature provides scant information with enough groundedness to explain firms' behaviors. The present research is an indepth case study, following the assumptions and procedures of Grounded Theory methodology, with the purpose of generating a set of hypothesis to explain strategic management of small building firms, according to what has emerged as relevant for the managers. Primary data were gathered through non-structured interviews with five managers to investigate why and how the firm has adapted to environmental changes in the last 20 years. A total of 595 minutes of interviews were analyzed using ATLAS/ti software. The core category that emerged from data was coping with risk. For the managers, to strategically manage the firm is to deal successfully with a difficult situation that threats firm survival. The developed grounded theory explains under what environmental and internal conditions patterns of coping with risk are used. Existing literature related to strategic management were confronted to the findings; most of them helped to explain the phenomena in some way, but none was able to grasp what was going on in terms of control and of relevance to the actors.
\end{abstract}

Key words: strategic management; turbulent environment; small firms; grounded theory. 


\section{INTRODUÇÃo}

As principais correntes teóricas sobre estratégia competitiva enfatizam o desenvolvimento e a verificação de teorias em contexto no qual firmas, geralmente de grande porte, agem no sentido de maximizar o lucro (rent seekers), moldar a dinâmica competitiva, ou serem por ela moldadas. Contudo, quando se considera um contexto específico, característico do ambiente econômico brasileiro, no qual o governo, em todos os níveis, promove mudanças institucionais e drásticas mudanças econômicas, as principais correntes teóricas sobre estratégia competitiva não fornecem explicações suficientes sobre o comportamento estratégico das firmas.

Apesar de haver falta de aderência entre a realidade local e os modelos estrangeiros, a pesquisa em estratégia no Brasil parece carecer de estudos mais aprofundados no que tange à explicação das idiossincrasias nacionais. Bignetti e Paiva (2002) realizaram um estudo da publicação em estratégia no Brasil no principal congresso da área, o Encontro Anual da Associação Nacional dos Programas de Pós-Graduação em Administração (ENANPAD), de 1997 a 2001. Os autores concluíram que "os modelos estrangeiros e muito especialmente anglosaxônicos imperam na academia brasileira e ocultam esforços isolados de desenvolvimento de uma abordagem nacional mais adequada às condições competitivas do mercado brasileiro" (Bignetti e Paiva, 2002, p. 115).

Além da carência teórica, há a metodológica que, entre outros efeitos, impede o acúmulo de conhecimento na área. Em levantamento da produção científica em estratégia, na última década, nos principais periódicos e congressos científicos nacionais, Bertero, Vasconcelos e Binder (2003) constataram que cerca de 43\% das publicações adotaram métodos qualitativos de pesquisa que, na realidade, refletem o "predomínio de estudos de caso, que a rigor são freqüentemente 'exemplos', não atendendo às exigências do protocolo habitual para estudos de caso enquanto pesquisa academicamente válida” (Bertero, Vasconcelos e Binder, 2003, p. 57).

Considerando isso, a presente pesquisa tem o intuito de atenuar a carência teórica e metodológica no desenvolvimento de explicações plausíveis para o comportamento estratégico das firmas no contexto brasileiro.

Principalmente a partir da década de 80, no Brasil, vários choques econômicos mudaram as relações contratuais entre firmas, congelaram preços e alteraram os sistemas de tributação. Aliam-se a isso variações significativas nas políticas 
monetárias e de controle da inflação, na moeda corrente e nos níveis de crédito para financiar a produção e a demanda (Baer, 1996).

Nesse contexto, pode-se inferir que a turbulência ambiental enfrentada pelas organizações brasileiras não é causada, principalmente, pela dinâmica competitiva - inovações tecnológicas e novos entrantes, como é considerado nas principais correntes teóricas no campo da estratégia - mas pelos efeitos da atuação de um governo, cujas características encontram paralelo com as sugeridas por Pearce (2001) para caracterizar governos não-facilitadores. Segundo a autora, tais governos são erráticos na tentativa de garantir a estabilidade contratual, fracos na implementação de suas leis e hostis para os empreendedores. Como conseqüência, as empresas que atuam nesse contexto institucional se organizam de maneira diferente daquelas que atuam em contextos caracterizados por um governo facilitador.

Propomos ${ }^{(1)}$ neste artigo que o relacionamento entre pequenas empresas e atores ambientais, em ambiente turbulento e com forte influência governamental, pode ser explicado por um processo social, no qual firmas, com pouca capacidade de influenciar o ambiente em proveito próprio, lidam com adversidades impostas a elas pelos atores ambientais e agem no sentido de maximizar sua longevidade em detrimento da maximização dos ganhos econômico-financeiros. Denominamos esse processo de administração do risco.

Neste artigo, são apresentados os elementos explicativos do processo de administração do risco, inferidos a partir de um estudo na indústria de construção de edificações. Altamente atomizada e basicamente constituída de pequenas empresas, geralmente familiares, a indústria de construção de edificações é particularmente afetada por decisões judiciais e políticas governamentais, principalmente devido à relevância social de seu produto, à relevância econômica e social de sua atividade e ao impacto em questões ambientais e de desenvolvimento municipal.

A pesquisa foi desenvolvida segundo a metodologia da Grounded Theory (Glaser e Strauss, 1967; Strauss e Corbin, 1998), cujo objetivo é a geração e a integração de um conjunto de proposições em uma teoria substantiva capaz de explicar o fenômeno que, identificado nos dados, emergiu como relevante para os envolvidos.

Esta pesquisa é produto dos estudos acerca da adaptação estratégica de empresas a ambientes turbulentos e com forte influência governamental que, há oito anos, vêm sendo desenvolvidos pelos autores, juntamente com outros pesquisadores, seguindo uma orientação teórico-metodológica de cunho processualista e contextualista. Nesse tipo de orientação, assumem-se que as estratégias da firma 
são formuladas a partir das construções mentais dos dirigentes sobre as mudanças ambientais (Child, 1972, 1997; Smircich e Stubbart, 1985) e que as mudanças estratégicas organizacionais devem ser compreendidas a partir do estudo do processo no qual elas se desenvolveram (Pettigrew, 1985, 1987; Van de Ven, 1992).

Inicialmente são descritos os procedimentos metodológicos utilizados e, em seguida, são apresentados os principais elementos do esquema teórico de administração do risco. Por fim, é apresentada uma síntese das comparações entre as principais correntes teóricas encontradas na literatura e os resultados da teoria substantiva desenvolvida neste estudo.

\section{Método}

Esta pesquisa utilizou um design de estudo de caso simples, de caráter contextual e processual (Pettigrew, 1985, 1987; Van de Ven, 1992), com a intenção de geração de teoria substantiva, utilizando o método da Grounded Theory (Merriam, 1998; Strauss e Corbin, 1998).

A Grounded Theory tem origem no Interacionismo Simbólico (Goulding, 2002), é apresentada como abordagem de pesquisa qualitativa e interpretativa e foi desenvolvida inicialmente por Glaser e Strauss (1967). Ela foi escolhida como opção metodológica desta pesquisa por oferecer uma série de procedimentos que aumentam a credibilidade dos resultados e possibilitam sua posterior verificação e escrutínio público; por ser um método interpretativista que se preocupa em explicar a ação coletiva como resultado da intersubjetividade dos indivíduos e suas relações com o ambiente e a sociedade; e, finalmente, pelo fato de encorajar a criatividade e a descoberta de problemas multifacetados e relevantes para os envolvidos, ao mesmo tempo que atenua a subjetividade do pesquisador.

A Grounded Theory gera teoria substantiva que difere da teoria formal, porquanto, ao passo que a última é mais geral e se aplica a espectro maior de problemas, a primeira é específica para determinado grupo ou situação e não visa a generalizar além da sua área substantiva (Glaser e Strauss, 1967; Strauss e Corbin, 1998).

O método utiliza a inferência abdutiva (Haig, 1996; Wirth, 1998), em que as causas da ação são interpretadas a partir dos efeitos observados, e não permite que pressuposições teóricas sejam forçadas a adequar-se aos dados. Como resultado da aplicação de suas técnicas, a teoria emerge dos dados e deve ser coerente com a realidade da área substantiva especificada para o estudo. 
O design deste estudo de caso simples compreendeu um conjunto de procedimentos e técnicas, com base nos roteiros propostos por Eisenhardt (1989), Pandit (1996) e Strauss e Corbin (1998). As etapas principais foram: (1) definição da questão de pesquisa; (2) trabalho no campo, com sobreposição de coleta e análise; (3) análise, com identificação das categorias conceituais e seus interrelacionamentos, amostragem teórica e teste das proposições; (4) comparação das proposições com a literatura existente; (5) fechamento, refino da teoria e redação do relatório final.

Antes de explicitar os procedimentos metodológicos utilizados, é importante ressaltar que o método da Grounded Theory se preocupa principalmente com a explicação de como determinado grupo resolve problemas em situações específicas, tal como pode ser constatado nos trabalhos publicados em Strauss e Corbin (1997). A explicação é fornecida por meio de um conjunto de proposições sobre quando e como determinadas ações são implementadas. Tais proposições são organizadas em torno de uma categoria central, que representa um processo social relevante para os envolvidos.

Por isso deve-se entender este estudo de caso simples como fornecedor de exemplos da ocorrência de um processo social que é relevante para os dirigentes de pequenas empresas, quando eles, ao administrarem estrategicamente empresas com pouco poder para influenciar o ambiente em proveito próprio, têm de lidar com situações adversas, particularmente induzidas pela ação governamental. Mesmo no estudo de uma organização, tal processo pode ocorrer com grande variabilidade, o que resulta em vários padrões de comportamento estratégico organizacional. O design de estudo de caso possibilita, por sua vez, a investigação em profundidade das causas e conseqüências dos padrões de comportamento.

Em estudos de caso com intenção de geração de teoria substantiva (Merriam, 1998), os padrões de comportamento estratégico são identificados e sistematizados nas categorias da teoria substantiva gerada, as quais devem possuir um nível de abstração que transcenda as especificidades de cada dirigente e da empresa estudada, no entanto sem que sejam extrapolados os limites da área substantiva. "O nível de abstração e conceituação em estudos de caso interpretativos pode variar de relacionamentos sugeridos entre variáveis até a construção de teoria" (Merriam, 1998, p. 39).

É por essa capacidade de abstração e pela sistematização da variabilidade encontrada nos dados que uma teoria substantiva adquire poder explicativo e não pelo número de casos investigados, sejam eles indivíduos ou organizações (Strauss e Corbin, 1998). Ainda assim, a teoria substantiva deve ser flexível e 
permanecer aberta às novas descobertas, sendo sistematicamente checada com novos dados. Isso implica que, à medida que novos dirigentes são ouvidos e novos dados secundários referentes a outras empresas são coletados, a teoria substantiva vai sendo aperfeiçoada e não simplesmente rejeitada, caso sejam encontradas divergências.

Este estudo de caso teve como objeto uma pequena empresa, de administração familiar, construtora de edificações e que atua no município de Florianópolis, no Estado de Santa Catarina. Ela foi denominada neste trabalho pelo nome fictício de BETA Engenharia e Incorporações Ltda.

A seleção da empresa objeto do estudo de caso consiste em uma etapa fundamental para a qualidade da teoria substantiva. A BETA foi selecionada, principalmente, por três motivos: (1) em função de possuir as características típicas das empresas que atuam na construção de edificações, o que aumenta o poder explicativo da teoria; (2) em função do seu tempo de existência; este estudo exigia, no mínimo, 20 anos de existência, para que se pudessem captar todos os efeitos da turbulência ambiental; e (3) pela facilidade de acesso aos dados, ponto crucial para o desenvolvimento de uma teoria substantiva de qualidade.

As fontes utilizadas geraram dois tipos de dados: (1) dados primários, obtidos no campo pelo pesquisador, por meio de entrevistas não-estruturadas em profundidade (quando não foi permitida a gravação das entrevistas, foram tomadas notas); (2) dados secundários, como resultados financeiros de cada empreendimento da empresa, indicadores da conjuntura econômica do país e do nível de atividade da construção civil no município (pedidos de licenças e 'habite-se'), reportagens sobre eventos importantes no setor da construção civil ao longo do período focalizado e estudos de casos publicados sobre pequenas empresas construtoras. Os dados secundários serviram para aumentar a informação do pesquisador na área substantiva e para fazer triangulações, quando necessário.

As entrevistas não-estruturadas buscaram captar os significados atribuídos pelos entrevistados às suas experiências em eventos relevantes para a sobrevivência da empresa no período estudado. As entrevistas abordaram, além de acontecimentos da própria empresa, transformações na indústria e nos padrões de concorrência, e mudanças no comportamento do consumidor consoantes as flutuações macroeconômicas, da forma como tudo era percebido pelos dirigentes.

Os entrevistados foram intencionalmente escolhidos. São pessoas que 
desempenharam, ou desempenham, o papel de tomadores de decisão na BETA. Todas têm nível superior: a entrevistada A é advogada e mestre em Administração (consultora jurídica da empresa desde a sua fundação e ocupante de cargo de direção desde 1997); os entrevistados B e D são sócios-fundadores, são engenheiros que trouxeram para a BETA experiência empresarial em firmas industriais de médio porte (o entrevistado D deixou a sociedade em 1997); o entrevistado C, também sócio-fundador, é administrador e desde a década de 70 atua na área comercial da construção civil em Florianópolis (deixou a sociedade em 1988); o entrevistado E é o responsável técnico da BETA, exerce importante influência na definição do produto e é o gerente de todas as operações técnicas da construtora para execução das obras. Ao todo foram cinco entrevistados, totalizando cerca de 595 minutos em nove entrevistas. Os entrevistados estão identificados ao longo do texto por letras do alfabeto (de A até E). Foram conduzidas três entrevistas com cada um dos entrevistados A e B (A1, A2, A3 e B1, B2 e B3) e uma entrevista com os outros (C1, D1, E1), com duração média de 66 minutos cada.

Mesmo com a sistemática verificação ds interpretações e dos dados durante a entrevista e a cada nova entrevista, foram feitas, no final do período de análise, sessões de checagem com os entrevistados A e B, para apresentar os principais elementos da teoria gerada e verificar o grau de coerência das interpretações. Foram apresentados os diagramas principais da teoria e o storyline da empresa, conforme sugerido por Strauss e Corbin (1998). Por questões de acesso, e como os entrevistados A e B são os principais dirigentes atuais da empresa, não foram feitas sessões finais de checagem com os demais entrevistados.

As sessões de entrevistas foram gravadas com a permissão dos entrevistados. Momentos em que não foram permitidas as gravações foram devidamente registrados. Houve acordo prévio para a não-publicação de cifras e números absolutos; no entanto a empresa não exerceu controle editorial sobre a publicação. Todas as entrevistas e notas foram devidamente transcritas. As entrevistas foram realizadas no período de julho a agosto de 2000; a checagem final e a discussão de pontos que não estavam claros ocorreram em novembro de 2001, em diálogos com os entrevistados.

As atividades de análise concentraram-se entre fevereiro e novembro de 2001, com apoio do software ATLAS/ti. Foram tomadas as devidas precauções para evitar os problemas decorrentes do uso de softwares no auxílio ao tratamento interpretativo de dados. Entre eles, está a alienação do pesquisador e a conseqüente reificação dos códigos, o que torna a análise mecânica e distanciada da essência dos dados.

A análise dos dados consiste em uma fase central na Grounded Theory e 
fundamenta-se no método das comparações constantes, o qual tem como objetivo a descoberta de propriedades e dimensões que caracterizam as categorias teóricas. A dimensionalização de categorias permite que novos dados sejam comparados aos existentes, o que aumenta a fundamentação empírica e a variabilidade dos elementos teóricos.

Para tratamento dos dados primários foram utilizados os procedimentos e técnicas sugeridos por Strauss e Corbin (1998) para sensibilização teórica e codificação. O processo de codificação foi divido em três fases não-lineares: codificação aberta, axial e seletiva. Após a identificação de categorias conceituais pela codificação aberta, a codificação axial examinou as relações entre categorias e subcategorias para explicitar causas e efeitos, condições intervenientes e estratégias de ação, que foram relacionadas em proposições. Finalmente, a codificação seletiva refinou e integrou todos os resultados, possibilitando a identificação da categoria central da teoria, a administração do risco.

O processo de análise foi orientado pela amostragem teórica (Strauss e Corbin, 1998) com o intuito de aumentar o poder explicativo da teoria e dar validade empírica às categorias descobertas durante o processo. As análises continuaram até que ganhos marginais no poder explicativo da teoria, para mais evidências coletadas, fossem aproximadamente nulos. Nesse ponto, próximo da saturação teórica (Strauss e Corbin, 1998), foi tomada a decisão de interromper o processo e iniciar a fase de confecção dos relatórios.

Os dados secundários foram considerados na análise tanto como subsídios à sensibilização, auxiliando nas comparações teóricas, como referenciais para identificar divergências entre os dados objetivos e as percepções dos entrevistados, que serviam de fontes de novas descobertas, à medida que as causas dessas divergências eram exploradas.

Foram adotados os critérios utilizados por Kerlin (1997), adaptados de Sherman e Webb (1988), para avaliar a teoria gerada pelo método da Grounded Theory. A descrição e a contribuição para a qualidade da teoria de cada critério encontramse no Quadro 1.

Ao longo da pesquisa, foram utilizadas técnicas, com base em Guba e Lincoln (1982), Merriam (1998) e Strauss e Corbin (1998), que visavam a aprimorar a qualidade da teoria em cada um dos critérios perseguidos. Entre elas estão a triangulação pelo uso de múltiplas fontes de dados, o ataque à teoria por meio da ferramenta query do ATLAS/ti, checagem com os entrevistados, amostragem em diferentes contextos (ao longo da história da empresa) e auditorias do processo de pesquisa por meio da análise dos relatórios gerados pelo ATLAS/ti. Como 
conseqüência, avaliando-se a teoria quanto à coerência com a realidade dos entrevistados (fit), nenhum dos códigos foi tomado emprestado da literatura e todos emergiram dos dados.

\section{Quadro 1: Critérios para Avaliação da Teoria Substantiva}

\begin{tabular}{|c|c|c|}
\hline CRITÉRIOS & DESCRIÇÃO & CONTRIBUIÇÃO \\
\hline $\begin{array}{c}\text { Grau de } \\
\text { coerência (fit) }\end{array}$ & $\begin{array}{l}\text { As categorias da teoria devem ser derivadas } \\
\text { dos dados e não de preconceitos do } \\
\text { pesquisador. }\end{array}$ & $\begin{array}{l}\text { Confere credibilidade à teoria e permite } \\
\text { que seja entendida por terceiros que } \\
\text { não participaram do estudo. }\end{array}$ \\
\hline Funcionalidade & $\begin{array}{l}\text { A teoria deve explicar as variações } \\
\text { encontradas nos dados e as inter-relações } \\
\text { dos construtos, de forma a fornecer } \\
\text { capacidade preditiva acerca do fenômeno } \\
\text { explicado. }\end{array}$ & $\begin{array}{l}\text { Uma teoria substantiva funcional deve } \\
\text { ser entendida como teoria útil para os } \\
\text { envolvidos. }\end{array}$ \\
\hline Relevância & $\begin{array}{l}\text { A teoria deve emergir fruto da sensibilidade } \\
\text { teórica do pesquisador, que deve ser capaz } \\
\text { de identificar a categoria central mais } \\
\text { relevante para explicar o fenômeno. }\end{array}$ & $\begin{array}{l}\text { A relevância é verificada pelo } \\
\text { reconhecimento imediato do } \\
\text { significado da categoria central pelos } \\
\text { envolvidos. }\end{array}$ \\
\hline Flexibilidade & $\begin{array}{l}\text { A teoria deve ser passível de modificação, } \\
\text { permitindo que novos casos a enriqueçam } \\
\text { com a introdução de novas propriedades e } \\
\text { categorias. }\end{array}$ & $\begin{array}{l}\text { Uma teoria substantiva deve estar } \\
\text { aberta para o aprimoramento da sua } \\
\text { capacidade de generalização. }\end{array}$ \\
\hline Densidade & $\begin{array}{l}\text { A teoria deve possuir poucos elementos- } \\
\text { chaves e grande número de propriedades e } \\
\text { categorias relacionadas. }\end{array}$ & $\begin{array}{l}\text { A densidade confere maior validade aos } \\
\text { construtos da teoria. }\end{array}$ \\
\hline Integração & $\begin{array}{l}\text { Todos os construtos devem estar } \\
\text { relacionados a uma categoria central e ser } \\
\text { expressos em termos de proposições } \\
\text { derivadas de um esquema teórico. }\end{array}$ & $\begin{array}{l}\text { A integração evita a existência de } \\
\text { falhas na lógica explicativa da teoria. }\end{array}$ \\
\hline
\end{tabular}

Fonte: adaptado de Sherman e Webb (1988) por Kerlin (1997).

A construção do esquema teórico da categoria central administração do risco foi elaborada visando à funcionalidade da teoria e à sua integração. Todas as proposições estão organizadas em torno da categoria central e predizem sob que condições cada forma de administrar o risco é a mais adequada e quais as estratégias a serem utilizadas.

O critério de relevância é particularmente importante para estudos de caráter qualitativo como este, pois é forte evidência da qualidade, coerência e utilidade da teoria. A relevância pode ser medida pela reação dos entrevistados ao se depararem com a explicação fornecida pela teoria substantiva.

"Muito bem posto, muito bem colocado. Isso faz sentido, realmente. Eu nunca pensei que pudesse ver o negócio dessa maneira. Muitos empresários com quem converso não têm essa compreensão. Estão preocupados com quanto estão ganhando no empreendimento A ou B e não na explicação de como ganham dinheiro ou como administram seu negócio” (Entrevistado A). 
A densidade e a fundamentação empírica dos construtos que compõem a teoria também foram avaliadas. Ao todo, foram gerados 177 códigos, 678 citações e 50 notas de análise. Destes, 137 são códigos de primeira ordem, diretamente ligados às citações, e 40 são construtos teóricos abstratos. A relação entre códigos abstratos, códigos de primeira ordem e citações, de 40/137/678, respectivamente, fornece evidências do grau de densidade teórica, em que poucos construtos teóricos estão relacionados a um número significativo de outras categorias e citações. Isso reflete duas características desta teoria substantiva que são fundamentais para qualquer pesquisa indutiva: parcimônia e escopo (Glaser, 1992).

\section{O Que o Caso da Beta Revelou}

A BETA é uma empresa cujas origens remontam a 1980. Suas atividades principais incluem a compra do terreno, a coordenação da elaboração dos projetos técnicos, a preparação da incorporação imobiliária, a construção e a comercialização das unidades residenciais ou comerciais do empreendimento. Ao longo do período estudado, de 1980 a 2000, a BETA produziu, em média, de um a dois empreendimentos por ano, com um pico registrado de seis empreendimentos executados concomitantemente. Concluiu, desde a sua fundação até 2000, 22 empreendimentos de, em média, 5.800 metros quadrados, totalizando aproximadamente 129.000 metros quadrados de área construída.

A análise da história da BETA revelou ocorrências do processo que denominamos administração do risco. Características da indústria de edificações forneceram as condições geradoras da ocorrência desse processo. De 1980 a 2000, a turbulência ambiental e a influência governamental geraram drásticas mudanças conjunturais, com reflexo nos mercados locais das construtoras. Com efeito, a empresa passou por períodos estratégicos nos quais as características ambientais externas e internas fizeram com que ela adotasse formas diferentes de lidar com o risco inerente à atividade imobiliária.

A seguir, definem-se o conceito de administração do risco e as proposições teóricas principais derivadas dos dados; logo após, apresentam-se as formas, ou padrões de comportamento, utilizadas pela empresa para administrar o risco. 


\section{O Conceito de Administração do Risco}

Identificamos no discurso dos entrevistados que havia, por trás de suas ações, preocupações acerca de como as incertezas do ambiente influenciariam a longevidade da firma e a conseqüente manutenção do padrão de vida das famílias dos dirigentes que dela dependiam. Seguimos esse caminho e direcionamos a amostragem teórica no sentido de dar densidade às categorias associadas ao risco percebido pelos dirigentes. Surgiram, portanto, novas categorias, consideradas relevantes pelos entrevistados. Entre elas, as principais estão relacionadas à percepção dos dirigentes quanto à postura de credores e de clientes ao participarem de transações imobiliárias. Tais posturas emergiram como fatores importantes na explicação da ação gerencial.

Ao longo do processo de pesquisa, algumas categorias e proposições foram desprezadas por falta de validade empírica; as que se mostraram fiéis aos dados foram integradas em um esquema teórico, que tem como categoria central o conceito de administração do risco. Esta seção expõe seus elementos teóricos e define sua categoria central.

A atividade imobiliária possui riscos inerentes à sua natureza, que são distribuídos ou compartilhados entre os envolvidos nas operações. Particularmente, os credores (instituições financeiras) e o mercado (clientes) são os mais relevantes para os dirigentes. Risco, como definido aqui, reflete a incerteza quanto aos resultados futuros auferidos pelos envolvidos, sejam resultados positivos ou negativos. Para os credores, reflete-se no recebimento do capital emprestado; para os clientes, na entrega efetiva da obra; para os dirigentes (ou para a firma), o risco do negócio pode ser representado pela possível perda de longevidade da empresa.

Apesar de refletir tanto ganhos como perdas futuras, para as firmas o risco do negócio está mais associado ao prejuízo e à conseqüente perda de longevidade, do que ao potencial de ganhos futuros; sua medição pode ser feita de forma aproximada pelo montante de capital próprio investido em cada projeto.

“A preocupação era sobrevivência no curto prazo, para salvar a empresa emergencialmente dos choques do governo, e longevidade no longo prazo" (Entrevistado A).

A inter-relação da firma com credores e mercado emergiu dos dados, indicando maior poder para o binômio mercado-credores, constituindo-se, assim, no principal definidor da distribuição dos riscos entre os envolvidos; ou seja, para os dirigentes, a postura dos credores e do mercado perante os 
riscos de participarem das transações imobiliárias define a distribuição do risco entre eles e as empresas e lhes impõe restrições a que não se podem furtar.

"Hoje o mais importante são os fatores externos, realmente!

A empresa está limitada” (Entrevistado B).

Com base no exposto, o significado de administração do risco deve ser ampliado, incorporando significados de termos como 'superação', 'fazer frente às dificuldades' e 'lidar com uma situação difícil e incerta'(2).

Os dados revelaram que no relacionamento entre firma e ambiente, a possibilidade de transferir uma parcela do risco para o ambiente sempre era aproveitada ao máximo, mesmo que isso resultasse em retornos inferiores. Esse padrão de comportamento, identificado nos dados, possibilitou a elaboração da hipótese fundamental da teoria substantiva.

$\mathrm{H}_{1}$ : Em ambiente turbulento e com forte influência governamental, as pequenas empresas aproveitam, ao máximo, o potencial de transferência de risco para 0 ambiente.

A hipótese acima, derivada dos dados após os exercícios interpretativos de análise e síntese, inerentes a Grounded Theory, é considerada fundamental para a teoria substantiva gerada, porquanto, caso ela se confirme, as demais proposições da teoria, também derivadas dos dados, podem ser consideradas.

O potencial de transferência do risco, ou seja, o tamanho da parcela do risco possível de ser transferido, era determinado por condições externas à empresa, revelando forte determinismo ambiental percebido. O risco somente podia ser transferido pela empresa, se credores e mercado estivessem dispostos a absorvêlo. Em outras palavras, a percepção dos dirigentes quanto à disposição de credores e clientes em absorver o risco determinava as possíveis formas de atuação estratégica da construtora. Esse relacionamento está expresso na seguinte proposição.

$P_{1}$ : A forma como dirigentes percebem a postura de credores e do mercado perante o risco de participarem nas transações imobiliárias, determina o nível de risco transferido e a forma de administrar o risco pela empresa.

Partindo do pressuposto de que a empresa aproveitava o máximo potencial de transferência do risco $\left(\mathrm{H}_{1}\right)$, a decisão por assumir mais risco deveria ser considerada como incremento de risco. Essa decisão visava à otimização do risco para aumentar a probabilidade de sobrevivência da empresa no longo prazo 
e era influenciada por fatores internos: o contexto estrutural interno e o esquema cognitivo dos seus dirigentes. A decisão levava em consideração: (1) os custos em adaptar a estrutura atual para operar com mais risco; (2) as incertezas da demanda futura; (3) os custos psicológicos, quando as decisões necessárias para atuar com mais risco vão de encontro aos valores do dirigente; (4) a manutenção do padrão de vida das famílias que dependem da empresa. A relação entre as formas de administrar o risco e as condições internas da empresa está explicitada na proposição abaixo.

$P_{2}$ : $O$ contexto estrutural interno e o esquema cognitivo vigente dos dirigentes contribuem para estabelecer o incremento de risco, definindo o risco incorrido pela empresa e, conseqüentemente, a forma de administrar esse risco.

Analiticamente, as posturas de credores e do mercado perante o risco formam as condições causais da teoria. O contexto estrutural interno e o esquema cognitivo vigente dos dirigentes formam as condições intervenientes, que alteram o efeito das condições causais.

Os padrões de comportamento, ou formas de administração do risco, podem ser inferidos a partir da série de mecanismos utilizados pela empresa. A análise dos dados revelou que tais mecanismos são utilizados para mitigar o risco, seja transferindo-o para o mercado, quando as condições contextuais externas permitiam, seja lidando com uma parcela desse risco que deveria ser absorvido. Por exemplo, a transferência do risco pode ocorrer por meio de repasse da dívida para o banco ou por regimes de construção a preço de custo. Já a absorção do risco, quando a empresa não está capitalizada, exige a utilização de estratégias que a tornam dependente dos credores. Essas evidências possibilitaram a elaboração da terceira proposição.

$P_{3}$ : Ao administrarem 0 risco, pequenas empresas utilizam estratégias de transferência do risco para o ambiente ou estratégias para lidar com o risco absorvido.

\section{Formas de Administração do Risco}

Administrar o risco, para os dirigentes da BETA, compreendia duas tarefas: (1) analisar o ambiente, para identificar a parcela de risco que podia ser transferida pela empresa ao ambiente (risco transferido); e (2) decidir sobre o nível de risco em que a empresa iria incorrer (risco incorrido). As duas tarefas acima consistem em duas propriedades da categoria central da teoria, risco transferido e risco incorrido, que, juntamente com a propriedade retorno 
esperado, definem os padrões de comportamento, ou formas de administrar o risco, que foram identificados nos dados. O Quadro 2 sintetiza as definições de cada forma a partir das respectivas dimensões das propriedades, bem como o sentido do fluxo do risco entre os envolvidos (mercado, empresas e credores).

\section{Quadro 2: Formas de Administrar o Risco Identificadas na História da BETA}

\begin{tabular}{|c|c|c|c|c|c|c|}
\hline \multirow{2}{*}{ FORMA } & Risco & Risco & Retorno & \multicolumn{3}{|c|}{ Fluxo do risco } \\
\cline { 5 - 7 } & Incorrido & Transferido & Esperado & Merc & Emp & Cred \\
\hline REPASSADOR & médio & médio & alto & & & \\
\hline ENTREHEIRADA & baixo & alto & baixo, alto & & & \\
\hline médio, alto & baixo & médio, alto & & & \\
\hline
\end{tabular}

É importante ressaltar que a classificação proposta não tem como objeto a firma, mas o seu comportamento estratégico, podendo, portanto, uma firma migrar de um tipo para outro, quando as condições causais e intervenientes provocarem uma mudança de comportamento. Isso foi o que aconteceu no caso da BETA ao longo da sua história.

\section{Repassando o Risco (de 1980 a 1986)}

Ao administrar o risco como repassadora, a BETA transferia o risco do mercado para os credores. Essa forma se manifestou nos anos iniciais da sua história, quando a empresa contraia empréstimos para financiar a produção, vendia as unidades em regime de incorporação a preço fechado e repassava sua dívida para os mutuários. Dessa forma, ela minimizava os riscos, transferindo-os para os credores, contudo ainda tendo que arcar com o risco da comercialização.

"Na verdade, o negócio era girar, e com menos [menor quantidade possível] de recursos próprios envolvidos” (Entrevistado B).

A forma repassadora de administração do risco parecia ser a mais adequada para a BETA, pois os credores estavam dispostos a absorver risco e os clientes estavam confiantes, ou seja, dispostos a adquirir um imóvel na planta e a participarem de financiamentos imobiliários junto a instituições financeiras. Credores absorvedores são caracterizados por possuírem recursos disponíveis para o financiamento da produção, liberados nas fases iniciais do cronograma de execução, e por não exigirem significativas contrapartidas pelas empresas. 
“O BNH tinha dinheiro à vontade. Tinha dinheiro para tudo. Era tanto dinheiro que eles financiavam tudo. Fazia-se o projeto, ia à CEF e ganhava o financiamento. Era um dinheiro muito fácil” (Entrevistado C).

Além de participar de financiamentos e de adquirir o imóvel na planta, um mercado confiante também é caracterizado por atribuir mais valor aos relacionamentos pessoais com o dono da empresa do que a uma análise racional dos ganhos futuros. Isso foi marcante para a BETA neste período; tanto que ao conjunto de relacionamentos que os líderes da empresa mantinham com os clientes, e que eram determinantes no fechamento dos negócios, denominamos ativos sociais.

"Naquele tempo, além da concorrência ser menor, vendia-se muito mais rápido. O [Entrevistado C], então, que conhecia o mercado [...], já começava antes a conversar com amigos, corretores e quando lançava o prédio de 20 apartamentos era tudo vendido em 60/90 dias. Era brincadeira” (Entrevistado B).

Com condições favoráveis de mercado confiante e credores absorvedores, a empresa ficava em posição que ia ao encontro do trade-off clássico risco-retorno. Ou seja, os retornos esperados pelos dirigentes eram anormais para o nível de risco incorrido.

"Na incorporação a preço fechado, o lucro era em função do preço. Estimava-se, fazia-se um orçamento [...], mas naquele tempo o mercado [...], não vou dizer que a margem era de 3 por 1 , de 2 e meio por 1 , mas se tinha uma margem muito grande. Primeiro que os terrenos eram baratos [...], hoje é caríssimo [...] se você for fazer uma permuta” (Entrevistado B).

\section{Entrincheirando-se (de 1986 a 1994)}

A obtenção de retornos anormais pela atuação da empresa como repassadora foi possível graças a um contexto externo favorável, no qual havia clientes confiantes e credores absorvedores. Nesse segundo período da história da BETA, apesar de o mercado continuar confiante, os credores não estavam mais dispostos a absorver o risco. Essa mudança de postura ocorreu em função, principalmente, das mudanças na conjuntura econômica que se seguiram após o Plano Cruzado em 1986.

Nesse período turbulento, que durou até a estabilização advinda com o Plano Real em 1994, os mecanismos de repasse do risco para os credores não eram tão eficientes quanto no período anterior, o que forçou a BETA a assumir posição 
segura de risco. Nesse caso, o comportamento da empresa pode ser entendido de forma análoga à proteção que as trincheiras proporcionam em ambiente hostil. Houve, portanto, entrincheiramento da BETA para se proteger da imprevisibilidade causada pelas mudanças econômicas e institucionais.

Comparando com a atuação como repassadora de risco, a forma entrincheirada parecia ser a mais adequada, quando os credores reduziam a disponibilidade de financiamento para a produção e as condições econômicas não permitiam a utilização de financiamentos de longo prazo de modo seguro pelas empresas, nem a confecção de orçamentos confiáveis. Isso era marcante nesse período instável, em que havia alta inflação, controle no preço dos fatores de produção e mudanças freqüentes nas regras contratuais. Nessas condições de alta turbulência, a BETA, então com escassez de capital próprio para financiar suas atividades, percebeu que a alternativa mais adequada era a redução máxima do risco incorrido no negócio.

O entrincheiramento, por sua vez, exigia que os clientes estivessem dispostos a assumir o risco. Por isso a BETA aumentou sua orientação para o mercado, principalmente no que diz respeito à imagem e à reputação para manter o cliente confiante. O entrincheiramento era implementado por meio da adoção de regimes de construção a preço de custo, no qual os clientes assumiam o risco da operação, na medida em que eram eles que arcavam com as despesas reais contabilizadas no período e, conseqüentemente, assumiam as divergências entre o orçado e o previsto. Nesse tipo de regime de construção, a remuneração da construtora ocorria pelo pagamento periódico de uma taxa de administração.

"Aí foi quando a gente optou por mudar o sistema de incorporação. Em vez de continuar correndo o risco de incorporação a preço fechado, a gente resolveu fazer incorporação a preço de custo, o que daria uma margem menor, mas segura” (Entrevistado B).

\section{Lidando com o Risco Absorvido (de 1994 até 2000)}

Os dados também revelaram que determinadas empresas concorrentes da BETA adotaram comportamento oportunístico, ao realizarem obras por administração com orçamentos subestimados ou despesas superfaturadas, causando a perda de confiança do cliente com esse regime de construção.

"Existem condomínios que foram feitos assim, que colocavam o que há de mais caro na praça. Tinha condomínio que a gente sabia, pois as pessoas vinham falar que demoravam” (Entrevistado D).

O cliente, então, passou de confiante para cético. Os credores, por sua vez, 
pressionados por obter resultados positivos e pela redução da disponibilidade de financiamentos imobiliários, tornaram-se mais exigentes. Nesse caso, não era permitida a transferência do risco pela BETA, seja para os credores, seja ou para o mercado, tal como era possível na atuação como repassadora ou entrincheirada.

O mercado cético era caracterizado pela sua baixa disposição em participar de financiamentos de longo prazo e em sistemas de contratação nos quais tinha que assumir risco, como é o caso dos regimes de construção a preço de custo. Também era caracterizado pela resistência dos clientes em adquirir o produto em fase de projeto, preferindo a pronta-entrega, e pela valorização da imagem e reputação da empresa em relação ao seu histórico de negócios.

"Quando nós acabamos de construir esses dois blocos, eu tinha vendido $50 \%$; quando os pintores estavam pintando, vendi os outros $50 \%$, e olha que uma pessoa conhecida como eu!” (Entrevistado C).

Já os credores exigentes impunham resistências e entraves burocráticos na liberação dos recursos, geralmente destinados para a demanda e menos para a produção. A sua liberação ocorria em fases mais avançadas da execução do projeto e exigiam significativas contrapartidas das empresas.

Em situações desfavoráveis de credores exigentes e clientes céticos, a empresa não conseguia repassar o risco nem se proteger nas trincheiras e a forma mais adequada para a BETA parecia ser a que denominamos absorvedora. Duas opções de atuação como absorvedora foram identificadas nos dados: ou a empresa se submetia às exigências dos credores ou ela decidia por financiar sua própria atividade. O incremento de risco, que é representado pelo financiamento de suas próprias atividades (ou a decisão de não incorrer nele e atuar de forma dependente dos credores), podia ser explicado por características econômicas, como o nível de capitalização da empresa, e por características subjetivas, como a personalidade do líder da empresa.

No caso da BETA, o financiamento das atividades com capital próprio da empresa ia ao encontro do que o líder considerava como sendo o papel do banco e da empresa. O que não foi o caso de suas principais concorrentes que atuavam “como um banco", financiando suas próprias atividades.

"Hoje o pessoal lança uma obra e faz a poupança em não sei quantos meses, financia direto. Eu não gosto, pois não é minha função, não sou banco, a empresa é construtora. Então, não tem nada a ver" (Entrevistado B). 
Atuando como dependente do credor, a empresa incorria em um nível de risco menor do que financiando sua própria atividade. Entretanto tal posição confortável e protegida, em contexto em que credores são exigentes e mercado é cético, custa para empresa perda do seu nível de rentabilidade; ou seja, credores e clientes (no caso das construtoras, as imobiliárias) apropriavamse do potencial de lucro da empresa. A empresa se submetia a isso em favor de ganhos de longevidade e manutenção do padrão de vida das famílias que dela dependiam.

\section{INTERPRETAÇõES TEÓRICAS}

Esta pesquisa foi motivada, em grande parte, pela incapacidade das teorias gerais de adaptação estratégica de explicarem a adaptação de pequenas empresas a ambientes turbulentos e com forte influência governamental. Uma análise comparativa revela contrastes entre as principais correntes teóricas sobre adaptação estratégica e os conceitos desta teoria substantiva.

A classificação proposta por Lewin e Volberda (1999), que agrupa as principais correntes teóricas (ou os paradigmas dominantes, segundo os autores) sobre adaptação estratégica de acordo com suas origens na Economia, na Teoria das Organizações e na Sociologia, foi utilizada para orientar a comparação. O Quadro 3 apresenta os pressupostos das correntes teóricas analisadas mais relevantes para a teoria substantiva de administração do risco, apontando as principais divergências e convergências entre elas e a teoria gerada.

$\mathrm{O}$ alto grau de determinismo ambiental e o baixo poder de agência da BETA, percebido pelos dirigentes na maioria dos períodos de sua história, nos quais o binômio credores-mercado determinava a parcela do risco possível de ser transferida pela empresa, reduzem a eficácia da intencionalidade gerencial e sugerem a existência de mecanismos de seleção ambiental na indústria, em detrimento da efetividade das ações que visam à adaptação da empresa (Hrebiniak e Joyce, 1985). Das propriedades ambientais sugeridas por Child (1997), as propriedades econômicas e institucionais foram responsáveis pelo determinismo percebido, e as propriedades relacionais refletiram a baixa capacidade de negociação e poder de influenciar o ambiente por parte dos dirigentes.

As propriedades relacionais foram influenciadas pela baixa capacidade de associação entre as empresas, ilustrada pela incapacidade de usar os ativos sociais de forma não-rival, e pela existência de comportamentos oportunísticos por parte dos concorrentes, o que contribuiu para que a empresa saísse da posição segura 
oferecida pelo entrincheiramento no segundo período de sua história. Em suma, esses fatores comprometeram a capacidade da empresa de declarar (enact) seu ambiente e de absorver a complexidade ambiental.

\section{Quadro 3: A Literatura e a Teoria Substantiva de Administração do Risco}

\begin{tabular}{|c|c|}
\hline $\begin{array}{l}\text { PARADIGMA } \\
\text { DOMINANTE }\end{array}$ & $\begin{array}{l}\text { IMPLICAÇÕES PARA A TEORIA SUBSTANTIVA } \\
\text { DE ADMINISTRAÇÃO DO RISCO }\end{array}$ \\
\hline $\begin{array}{l}\text { ORGANIZAÇÃO } \\
\text { INDUSTRIAL }\end{array}$ & $\begin{array}{l}\text { Não explicita a questão da percepção do risco na análise estrutural da } \\
\text { indústria. } \\
\text { Não considera o trade-off entre longevidade e risco incorrido pela empresa e } \\
\text { sua influência nos objetivos organizacionais. } \\
\text { As estratégias não conseguem erguer barreiras de entrada contra forças que } \\
\text { agem indiretamente, como a intervenção do governo na economia. } \\
\text { Não considera o caráter reativo das ações estratégicas das empresas, fruto } \\
\text { das diversas crises na indústria. } \\
\text { Não considera o fluxo de risco entre os envolvidos da indústria. }\end{array}$ \\
\hline $\begin{array}{l}\text { TEORIA DA } \\
\text { FIRMA BASEADA } \\
\text { EM RECURSOS } \\
(\text { RBV })\end{array}$ & $\begin{array}{l}\text { Os ativos sociais mostraram-se recursos essenciais, visto que são } \\
\text { acumulados pela empresa ao longo do tempo e não são facilmente } \\
\text { negociáveis entre as firmas. }\end{array}$ \\
\hline $\begin{array}{c}\text { TEORIA } \\
\text { CONTINGENCIAL }\end{array}$ & $\begin{array}{l}\text { Por se limitar ao estabelecimento de relações de causa e efeito entre } \\
\text { ambiente e estrutura, não consegue captar toda a essência do fenômeno que é } \\
\text { relevante para os dirigentes quando gerenciam uma pequena empresa, com } \\
\text { pouco poder de influenciar seu ambiente em proveito próprio, em ambiente } \\
\text { hostil. }\end{array}$ \\
\hline $\begin{array}{l}\text { ESCOLHA } \\
\text { ESTRATÉGICA }\end{array}$ & $\begin{array}{l}\text { O processo de adaptação estratégica, tal como explicado pela teoria } \\
\text { substantiva de administração do risco, não encontra apoio em uma visão } \\
\text { dicotômica determinista-voluntarista, mas na integração do determinismo } \\
\text { ambiental com o nível de escolha estratégica da empresa. } \\
\text { Devido ao alto determinismo ambiental percebido, as propriedades } \\
\text { ambientais econômicas e institucionais mostraram-se mais importantes do } \\
\text { que as propriedades relacionais, sugerindo que a seleção ambiental explica } \\
\text { melhor o fenômeno do que a intencionalidade gerencial em adaptar a } \\
\text { empresa ao ambiente. }\end{array}$ \\
\hline $\begin{array}{l}\text { ECOLOGIA } \\
\text { POPULACIONAL }\end{array}$ & $\begin{array}{l}\text { A não-efetividade da ação gerencial sugerida pela Ecologia das Populações é } \\
\text { particularmente evidente na atuação como absorvedora, dependente do } \\
\text { credor. }\end{array}$ \\
\hline $\begin{array}{c}\text { TEORIAS } \\
\text { INSTITUCIONAIS }\end{array}$ & $\begin{array}{l}\text { Os dados mostraram uma certa homogeneidade das formas de administrar o } \\
\text { risco na indústria, o que pode ter uma explicação plausível nos processos de } \\
\text { isomorfismo. }\end{array}$ \\
\hline
\end{tabular}

Com relação à explicação das fontes de vantagem competitiva, tanto o modelo de Porter (1980) como as perspectivas fundamentadas na eficiência dos recursos apresentaram contribuições e contrastes. Destacam-se a desconsideração no modelo de Porter (1980) de questões relacionadas ao risco percebido como um dos determinantes do poder de barganha entre os envolvidos e a incapacidade das estratégias competitivas genéricas de proporcionar posições seguras, livres de risco. Como conseqüência, a mensuração da atratividade da indústria, medida pelo modelo de Porter (1980), desconsidera a distribuição do risco entre os envolvidos. 
Do ponto de vista dos recursos, destacam-se os ativos sociais como recursos essenciais, cuja posse conferia à BETA vantagens sobre os concorrentes. Outro ponto digno de nota que a história da BETA revelou, foi que a importância da marca é inversamente proporcional à dependência dos ativos sociais como fonte de vantagem competitiva.

\section{ConsideraçõEs FinaIS}

Os resultados deste estudo de caso, desenvolvido com a intenção de geração de teoria substantiva pelo método da Grounded Theory, vão além da mera descrição e fornecem uma explicação plausível, não-trivial, na ótica dos dirigentes, da ocorrência de padrões de comportamento estratégico de pequenas empresas durante o processo de interação delas com atores ambientais poderosos, em ambiente hostil, caracterizado pela turbulência e pela influência governamental. A teoria substantiva gerada explica como e em que condições essas empresas adotam formas específicas de administração do risco imposto a elas pelo ambiente.

A hipótese fundamental da teoria substantiva de administração do risco é a de que pequenas empresas, nessas condições hostis, adotam ações para mitigar o risco e, conseqüentemente, garantir a sua longevidade, em detrimento da maximização dos seus retornos.

Apesar de os questionamentos sobre a perfeita racionalidade dos atores e a maximização dos resultados econômicos como objetivos principais da firma serem, há tempos, discutidos na literatura da área (Simon, 1945; Cyert e March, 1963), a teoria substantiva da administração do risco aborda tais questionamentos em contexto específico, na medida em que fornece os elementos explicativos do processo no qual pequenas empresas se submetem, na tentativa de garantir sua longevidade em detrimento da maximização dos ganhos econômicos.

O contraste dos resultados encontrados com a literatura sugere principalmente, o seguinte: a forma como o risco é distribuído entre os envolvidos deve ser considerada como indicadora da atratividade ambiental; os ativos sociais são fontes de vantagem competitiva, cuja importância é inversamente proporcional à importância da marca da empresa e da orientação para o mercado; o baixo nível de agência da empresa é influenciado pela sua incapacidade de usar os ativos sociais de forma não-rival; e a associação do baixo poder de influenciar o ambiente com o alto determinismo ambiental reduziu a importância da intencionalidade gerencial no sucesso da empresa, indicando que a seleção ambiental pode ser uma explicação plausível para compreender a evolução da indústria. 
É importante ressaltar que o método da Grounded Theory não tem a pretensão de testar teorias, mas de descobrir e elaborar hipóteses conceitualmente fundamentadas nos dados que podem vir a ser testadas, do ponto de vista estatístico, em outras pesquisas com design apropriado. Os resultado expostos neste artigo devem ser entendidos como provisórios e passíveis de modificação, à medida que novas variações são incorporadas à teoria. Por isso a explicação do processo de adaptação estratégica de pequenas empresas a ambientes turbulentos e com forte influência governamental continua à guisa de conclusão.

\section{Notas}

${ }^{1}$ Utilizamos a primeira pessoa do plural para escrever algumas passagens deste artigo pois, neste tipo de método, o pesquisador deve comprometer-se com os resultados, assumir sua identidade e revelar as razões de suas escolhas durante as análises. Somente dessa forma os resultados tornamse passíveis de avaliação pelo crivo do leitor, aumentando a validade e a confiabilidade da pesquisa.

${ }^{2}$ Um termo que sintetizaria a essência do fenômeno identificado nos dados é o verbo da língua inglesa to cope, que significa "lidar (com êxito) com uma situação difícil ou infortuita" (Procter, 1995, p 304); porém optamos por denominar esta teoria substantiva de teoria da administração do risco.

\section{Artigo recebido em 28.10.2003. Aprovado em 04.12.2003.}

\section{REFERÊNCIAS BiBLIOGRÁFICAS}

BAER, W.

A economia brasileira. São Paulo: Nobel, 1996.

BERTERO, C.;

VASCONCELOS, F.;

BINDER, $M$.

Estratégia empresarial: a produção científica brasileira entre 1991 e 2002. Revista de Administração de Empresas, v. 43, n. 4, p. 48-62, 2003.
BIGNETTI, L. P.;

PAIVA, E. L.

Ora (direis) ouvir estrelas!: estudo das citações de autores de estratégia na produção acadêmica brasileira. Revista de Administração Contemporânea, v. 6, n. 1, p. 105-125, Jan./ Abr. 2002.

CHILD, J.

Organizational structure, environment and performance: the role of strategic choice. Sociology, v. 6, p. 2-22, 1972. 
Strategic choice in the analysis of action, structure, organizations and environment: retrospect and prospect. Organization Studies, v. 18, n. 1, p. 43-76, 1997.

CYERT, R.;

MARCH, J.

A behavioural theory of the firm. Englewood Cliffs, NJ: Prentice Hall, 1963.

EISENHARDT, $\mathrm{K}$.

Building theories from case study research. Academy of Management

Review, v. 14, n. 4, p. 532-550, 1989.

GLASER, B.

Basics of grounded theory analysis. Mill Valley, CA: Sociology Press, 1992.

GLASER, B.;

STRAUSS, A.

The discovery of grounded theory: strategies for qualitative research. New York: Aldine de Gruyter, 1967.

GOULDING, C.

Grounded theory: a practical guide for management, business and market researchers. London: Sage Publications, 2002.

GUBA, E.;

LINCOLN, Y.

Epistemological and methodological bases of naturalistic inquiry. Educational Communication and Technology, v. 30, n. 4, p. 233-252, 1982.
HAIG, B.

Grounded theory as scientific method. In: NEIMAN, A. (Ed.). Philosophy of education 1995. Urbana: University of Illinois Press, 1996.

HREBINIAK, L.;

JOYCE, W.

Organizational adaptation: strategic choice and environmental determinism. Administrative Science Quarterly, n. 30, p. 336-349, 1985.

\section{KERLIN, R.}

Breaking the silence: toward a theory of women's doctoral persistence. Canada, 1997. Thesis (Ph.D.) University of Victoria.

LEWIN, A.;

VOLBERDA, $\mathrm{H}$.

Prolegomena on coevolution: a framework for research on strategy and new organizational forms. Organization Science, v. 10, n. 5, p. 519-534, Sept./Oct. 1999.

MERRIAM, S.

Qualitative research and case study applications in education. San Francisco: Jossey-Bass, 1998.

PANDIT, N.

The creation of theory: a recent application of the grounded theory method. The Qualitative Report, v. 2, n. 4, Dec. 1996.

PEARCE, J.

Organization and management in the embrace of government. Hillsdale, NJ: Lawrence Erlbaum, 2001. 
PETTIGREW, A.

Contextualist research: a natural way to link theory and practice. In: LAWLER, E. Doing research that is useful in theory and practice. San Francisco: Jossey-Bass, 1985.

Context and action in the transformation of the firm. Journal of Management Studies, v. 24, n. 6, p. 649-670, 1987.

PORTER, M.

Competitive strategy: techniques for analyzing industries and competitors. New York: Free Press, 1980.

PROCTER, P. (Ed.).

Cambridge International dictionary of English. Cambridge, MA: Cambridge University Press, 1995.

SHERMAN, R.;

WEBB, R. (Org.).

Qualitative research in education: focus and methods. New York: The Falmer Press, 1988.
SIMON, H.

Administrative behavior. New York: Free Press, 1945.

\section{SMIRCICH, L;}

STUBBART, C.

Strategic management in an enacted world. Academy of Management Review, v. 10, n. 4, p. 724-736, 1985.

STRAUSS, A.;

CORBIN, J. (Eds.).

Grounded theory in practice. London: Sage Publications, 1997.

Basics of qualitative research: techniques and procedures for developing grounded theory. 2 ed. London: Sage Publications, 1998.

VAN DE VEN, A.

Suggestions for studying strategy process: a research note. Strategic Management Journal, v. 3, p. 169188, 1992.

WIRTH, U.

Abductive inference. In: BOUISSAC, P. (Org.). Encyclopedia of semiotics. Oxford: Oxford University Press, 1998. 